\title{
Book Review: Corpus Approaches to Evaluation: Phraseology and Evaluative Language
}

\author{
Yang Chen ${ }^{1}$, Fei Deng ${ }^{1 *}$ \\ 1 School of Foreign Studies, South China Agricultural University, Guangzhou, CHINA
}

*Corresponding Author: Fei Deng, dengfei@scau.edu.cn

Citation: Chen, Y. and Deng, F. (2019). Book Review: Corpus Approaches to Evaluation: Phraseology and Evaluative Language. Pedagogical Research, 4(2), em0030. https://doi.org/10.29333/pr/5767

Published: May 9, 2019

Evaluation, as one of the most basic and important elements and functions in language use, has attracted more and more attention in the fields of language research and language teaching \& learning. Susan Hunston's book, Corpus Approaches to Evaluation: Phraseology and Evaluative Language, as the 13rd book of the Routledge Advances in Corpus Linguistics series, explores evaluation from the perspective of corpus linguistics. In this book, Hunston describes how to use corpus phraseological approaches, which are based on the exploitation of information technology, to study evaluative language in written discourse. This book offers innovative methods to explore evaluation and provides a new insight into English learning and teaching.

There are 9 Chapters in this book. Chapter 1 discusses the three fundamental terms in the book: evaluative language, phraseology and corpus linguistics. At the very beginning, Hunston defines evaluative language as: "evaluative language is that language which indexes the act of evaluation or the act of stance-taking. It expresses an attitude towards a person, situation or other entity and is both subjective and located within a societal valuesystem" (Hunston, 2013:1). Evaluation is prevalent in any text. Therefore, "finding a text or even a sentence without any trace of evaluation is a very challenging, if not impossible, task" (Alba-Juez \& Thompson, 2014: 5). However "evaluation is often expressed implicitly" (Hunston, 2013:3) and is very hard to trace. Thus it may pose great difficulties for EFL learners to see implied evaluative meanings in reading English texts. Hunston points out that this problem can be tackled by using corpus phraseological approach. In corpus linguistics, phraseology is a very general term "used to describe the tendency of words, and groups of words, to occur more frequently in some environments than in others" (Hunston, 2013: 5). It is "due to become central in the description of English" because "units of meaning are expected to be largely phrasal" (Sinclair, 2004: 30). Moreover, "units of meaning express attitude, often implicitly" (Hunston, 2013: 7). Hunston proposes that phraseology plays a number of roles in the study of evaluative language. In the following chapters, Hunston presents a series of empirical studies to support this argument.

Chapter 2 makes comments on four approaches to evaluation, focusing on differences and consensuses. The differences mainly lie in a disagreement in what kind of phenomenon "evaluation" is taken to be, including: (1) evaluation is an action; (2) evaluation is the set of words and phrases which express evaluative meaning; (3) evaluation is a set of meanings which might be expressed in a given text using a wide variety of language resources; (4) evaluation is a function performed by a text, or part of a text. The consensuses include: (1) evaluation is both subjective and intersubjective; (2) evaluation construes an ideology that is shared by writer and reader (or speaker and hearer); (3) there is broad range of lexical and other indicators of evaluative meaning; (4) evaluation is both contextual and cumulative; (5) evaluation involves a target, or object, and a source; (6) once researchers set themselves the task of identifying evaluation, it becomes difficult reliably to identify anything that is not evaluative.

Chapter 3 deals with status in written texts and multi-modal texts. This chapter first reviews the concept of status and the linguistic resources associated with it, including an exploration of the relationship between status and attribution. Then it takes the readers beyond written text into the world of documentary films, and presents 
how "status" might be applied to visual texts as well as verbal ones. There follows a discussion of how status is related to other concept, "Engagement" in Appraisal theory of Functional Linguistics that apparently account for roughly similar phenomena. The chapter includes numerous examples in which a proposition is identified along with markers of status. The author argues that one of the functions of evaluation is to reify texts and propositions by assigning them an epistemic status. The status which is assigned aligns a text or a proposition to a construed world.

Chapters 4 to chapter 8 focus on corpus phraseological approach to study evaluative language, as opposed to the text-based work discussed in the previous chapters. Chapter 4 discusses the relationship of the three concepts: evaluation, quantity and meaning. In this chapter the contributions of corpus linguistics to the study of evaluation are made central. The author raises three specific research questions: (1) How much of what kind of evaluative meaning occurs in a given corpus of texts? (2) Can algorithms be developed that will reliably identify evaluative meaning in a corpus of texts? (3) What is the contribution of "latent patterning" to evaluative meaning? In answering the first two questions, the author reviews the previous researches of evaluative language which applies corpus linguistics approach, including researches on stance, meta-discourse and sentiment analysis. In answering the third question, the author describes the operational model of units of meaning, which includes collocation, colligation, semantic preference and semantic prosody, among which semantic prosody refers to "a subtle element of attitudinal, often pragmatic meaning" (Sinclair, 2004:145), thus it can be inferred that units of meaning express evaluation implicitly. The author goes further to offer examples to support her argument that the identification of evaluative meaning depends on "latent patterning", that is, patterning in language that is not obvious to intuition or to language as it is observed in single texts. Rather, the patterning is apparent only when a lot of examples are perceived together in corpus' concordance lines.

Chapter 5 discusses modal-like expressions. This Chapter proposes two arguments, the first is that there is a category of linguistic items called modal-like expressions which can be seen to occur in concordance lines along with ordinary modal verbs; the second is that some verbs act as "attractors" of modal meaning, co-occurring with such meaning more frequently than other verbs do. Besides, this chapter explores how corpus methodologies contribute to the formation of such arguments. A mainly qualitative methodology which emphasizes reading concordance lines, and a mainly quantitative methodology which emphasizes calculating comparative frequencies are used to demonstrate the first argument and the second argument respectively.

Chapter 6 explores corpus approaches to investigating status. This chapter argues that propositions can be evaluated in terms of their status, using resources such as "status nouns". The author examines expressions that evaluate status in one corpus, looking at the contexts in which they typically appear, in order to build up a picture of common epistemological practices in the corpus under investigation. Corpus phraseological approach is also used in this chapter. The starting point is the items such as prepositions which frequently co-occur with a given word or phrase and the focus is the semantic similarity of the phrases incorporating those prepositions. By using this method, the author explores what is often said about propositions identified explicitly as being hypotheses, discoveries, assumptions and so on.

Chapter 7 discusses grammar patterns, local grammars and evaluation. This chapter deals with "local grammars" and "grammar patterns" in relation to evaluation. The author argues that patterns are of some but limited use as tests for different kinds of Appraisal (in Appraisal System). On the other hand, patterns are a very useful heuristic, identifying distinctions in evaluative meaning that the Appraisal System may overlook. This chapter also examines local grammars alongside other attempts to map meaning on to form, most notably FrameNet.

Chapter 8 deals with the relationship between phraseology, intensity and density. This chapter examines the role of phraseology in expressing the strength of evaluation. The author argues that "some phraseologies are frequently associated with evaluative meaning, to the extent that they are able to bring about semantic reversal and imply a meaning that would be otherwise missing from a text" (Hunston, 2013:164).

Chapter 9 provides a conclusion. It reviews the concepts of evaluative language, phraseology and corpus linguistics, and concludes a number of roles corpus investigation techniques play in the study of evaluative language. Then the author points out the directions of future studies.

In my opinion, this is an excellent book, which has great value for a variety of scholars and teachers, including EFL (English as a Foreign Language) teachers. As is pointed out in this book, phraseology has become central in the description of English. This implies that the main focus of teaching and learning English should be on (a) the commonest word forms in the language; (b) their central patterns of usage; and (c) the combinations which they typically form (Sinclair \& Renouf, 1988:150). Thus phraseological approaches have been applied to describe and explore evaluative language. On the other hand, as evaluation is prevalent in any text and it is often expressed implicitly, it may be difficult for EFL learners to infer implicit evaluation in English texts. Gui (2012) points out that Chinese EFL teaching has long been neglecting to explore evaluative meaning of propositional information. It has also been found out that many university students in China, even those English majors, who have good commands of English grammar, vocabulary and reading skills, yet fail to see implied evaluative meanings in reading 
texts, thus missing or even misunderstanding some important messages. Corpus phraseological approaches to the study of evaluative meaning provided by this book offers the teachers a new insight into how to promote English learners' reading literacy. Corpus techniques can be applied in reading teaching classroom. Teachers can set up specialized corpora for the reading class and guide the learners to read articles with the same topic by using corpus tools (keyword, collocates, concordance lines, etc.). To be more specific, first, teachers can guide learners to grasp aboutness (main idea) and sub-topics of the reading material quickly by retrieving and observing the keywords from the corpora; learners can search the information related to the topic quickly by reading the concordance lines horizontally which highlight the search items with their co-textual information on either side; second, teachers can guide the learners to use corpus approaches to explore the phraseologies of the keywords, and then to pay attention to the relation between phraseology and evaluative meaning from the level of "lexis" to the level of "discourse", and from literal meaning of words to meaning beyond words. In this way, the learners' in-depth reading ability (reading for the writer's hidden opinions, evaluative attitudes and ideologies) can be improved and they can read more critically. In sum, this is a thought-provoking and original book in the fields of language research, language teaching \& learning, discourse analysis, computer corpus linguistics and information technology, and it deserves much attention from the readers in all of those fields.

\section{ACKNOWLEDGEMENTS}

This paper is supported by the project of the 13th five-year plan for Guangzhou Philosophy and Social Science in 2018 (project number: 2018GZYB53) and the project of the 13th five-year plan for Guangzhou Philosophy and Social Science in 2019 (project number: 2019GZYB36).

\section{REFERENCES}

Alba-Juez, L. and Thompson, G. (2014). The many faces and phases of evaluation. In G. Thompson and L. AlbaJuez (eds.). Evaluation in context. Amsterdam: John Benjamins., 3-23. https://doi.org/10.1075/pbns.242.01alb

Gui, Shichun. (2012). A new view of language and communication. Foreign Language teaching and research, 44(5), 765774.

Hunston, S. (2013), Corpus Approaches to Evaluation: Phraseology and Evaluative Language. New York: Routledge.

Sinclair, J. (2004). Trust the Text: Language, Corpus and Discourse. London: Routledge.

Sinclair, J. and Renouf, A. (1998). A lexical syllabus for language learning. In R. Carter and M. McCarthy (eds.). Vocabulary and language teaching. London: Longman. 